\title{
The colours of chromium
}

\author{
From rubies to Rolls-Royce, Anders Lennartson explores the colourful history of chromium and its \\ coordination compounds.
}

A s a boy, I set up my own makeshift laboratory in my parents' basement. During my early chemical investigations, I acquired some chromium(III) chloride hexahydrate, a green salt that gave an equally green solution when dissolved in water. When I came back the next day, however, to my great surprise I found that the solution was now a violet colour. How could that be, I wondered?

An important property of chromium(III) complexes is that ligand exchange is slow. When I dissolved $\mathrm{CrCl}_{3} \cdot 6 \mathrm{H}_{2} \mathrm{O}-$ which is more properly represented by the formula $\left[\mathrm{CrCl}_{2}\left(\mathrm{H}_{2} \mathrm{O}\right)_{4}\right] \cdot \mathrm{Cl}\left(\mathrm{H}_{2} \mathrm{O}\right)_{2}$ - in water, it slowly reacted with the solvent to give the violet-coloured $\left[\mathrm{Cr}\left(\mathrm{H}_{2} \mathrm{O}\right)_{6}\right]^{3+}$ complex and free chloride ions. If I had had some chromium(III) sulfate to hand, I would have observed the opposite colour change; it exists as $\left[\mathrm{Cr}\left(\mathrm{H}_{2} \mathrm{O}\right)_{6}\right]^{3+}$ in the solid hydrate, but when an aqueous solution of this compound is heated, it turns from violet to green because of the slow dissociation of water ligands and coordination of sulfate ions. This property of $\mathrm{Cr}$ (III) makes it possible to isolate a wide variety of chromium(III) coordination compounds, and is why $\mathrm{Cr}^{3+}$, along with $\mathrm{Co}^{3+}$, was a big favourite amongst early coordination chemists like Alfred Werner.

In contrast to chromium(III), chromium(II) complexes can exchange their ligands rapidly, and addition of acetate to blue $\mathrm{CrCl}_{2}$ solutions precipitates red $\mathrm{Cr}_{2}(\mathrm{OAc})_{4}$, a compound that has a $\mathrm{Cr}-\mathrm{Cr}$ quadruple bond. Chromium also exists in higher oxidation states: black chromium(IV) oxide was used extensively in the good old days of magnetic tapes because of its ferromagnetic properties; unstable $\mathrm{CrF}_{5}(\mathrm{Cr}(\mathrm{v}))$ is a volatile red solid. If chromium(III) oxide (also known as chrome green) is heated with potassium carbonate and potassium nitrate, the mixture slowly

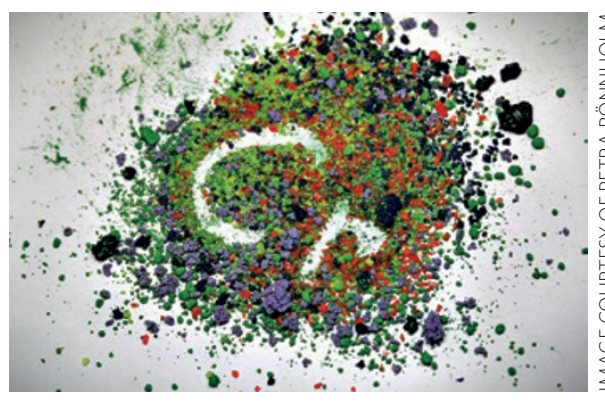

turns yellow. This colour change stems from the formation of potassium chromate, $\mathrm{K}_{2} \mathrm{CrO}_{4}$, in which chromium is found in oxidation state vi.

Other chromium(vi) compounds include the beautifully orange potassium dichromate, $\mathrm{K}_{2} \mathrm{Cr}_{2} \mathrm{O}_{7}$, red potassium trichromate, $\mathrm{K}_{2} \mathrm{Cr}_{3} \mathrm{O}_{10}$, and red chromium(vI) oxide, $\mathrm{CrO}_{3}$. The latter is an acidic oxide, and its aqueous solutions are referred to as chromic acid - with the addition of dilute sulfuric acid this becomes Jones reagent, used to convert alcohols to ketones or carboxylic acids. Acidic potassium dichromate is also used by organic chemists for the same reaction, with the added bonus that if a synthesis fails, a solution of $\mathrm{K}_{2} \mathrm{Cr}_{2} \mathrm{O}_{7}$ in sulfuric acid can be used to clean the dirty glassware, such is its oxidizing power.

It is now known that chromium(vI) compounds are toxic and may cause cancer, but previously they were popular in pigments such as $\mathrm{PbCrO}_{4}$ and $\mathrm{Pb}_{2} \mathrm{OCrO}_{4}$ (chrome yellow and chrome red, respectively). The colours of chromium have been highly admired since ancient times - rubies are nothing but crystalline aluminium oxide doped with chromium, and pink hues in sapphires also originate from traces of chromium in an aluminium oxide lattice. Emeralds, a form of beryl,

$\mathrm{Be}_{3} \mathrm{Al}_{2}\left(\mathrm{SiO}_{3}\right)_{6}$, derive their green colour from small amounts of chromium.

It seems more than appropriate, therefore, that chromium was named after the Greek word chroma - which means colour - by Louis Nicholas Vauquelin, who discovered the element in 1797 . The metal was not an immediate commercial success. Fifteen years after its discovery, Sir Humphrey Davy did not know much about chromium or its compounds when he wrote his famous text book Elements of Chemical Philosophy, but he did remark that chromic acid has a sour taste ${ }^{1}$. Tasting chemicals was obviously the order of the day, because in that very same year Jöns Jacob Berzelius wrote in his textbook that the aftertaste of the toxic chromic acid was harsh and metallic ${ }^{2}$. Berzelius also noted that the metal, although brittle, was very resistant to both acids and oxidation in air. We now know that this property comes from the fact that, when exposed to air, metallic chromium forms a very thin, but dense, oxide layer on its surface.

In the 1820s it was found that addition of chromium to steel made it resistant to rusting, but unfortunately the high carbon content of the chromium available at the time made these alloys brittle and useless for practical applications. When methods developed such that carbon-free chromium was produced in the 1890s, the situation changed. Stainless steel, which typically contains $8 \%$ chromium and $18 \%$ nickel, soon became widely used, and it remains one of the main applications of chromium today. The discovery, in the 1920 s, that a thin layer of shiny chromium could be electrolytically deposited on steel came as a delight to the automotive industry. What would a 1930s Rolls-Royce Phantom II be without its chrome plating?

\section{ANDERS LENNARTSON is at Chalmers} University of Technology, Department of Chemical and Biological Engineering, Polymer Technology, 41296, Gothenburg, Sweden. e-mail: anle@chalmers.se

\footnotetext{
References

1. Davy, H. Elements of Chemical Philosophy Part 1 Vol 1, 463 (J. Johnson, 1812).

2. Berzelius, J. J. Lärbok i Kemien Part 289 (Henr. A. Nordström, 1812)
} 